The Social Sciences 5 (4): 332-339, 2010

ISSN: $1818-5800$

(C) Medwell Journals, 2010

\title{
Certainty and Conventional Indirectness in Persian and American Request Forms
}

\author{
Abbass Eslami-Rasekh, Mansoor Tavakoli and Parisa Abdolrezapour \\ Department of English, Faculty of Foreign Languages, University of Isfahan, Iran
}

\begin{abstract}
Several studies have been carried out with the goal of investigating cross-cultural differences which exist between Persian and English, focusing on the realization of different speech acts in an Iranian context. This study focuses on the similarities and differences between Americans and Iranians with regard to the speaker's assumed expectations of compliance in choosing from the conventionally indirect spectrum. The question is how uncertain the speaker was that the addressee would comply with the request when she/he chose a particular conventionally indirect request. The participants consisted of 22 American native speakers studying at Fresno State University and 30 Iranian M.A. students studying English at Isfahan University. The data for this study were collected via role plays, post-performance interviews and questionnaires. The results obtained show that in comparable situations, the Americans are generally more certain that the addressee would comply with the request than Iranians. It is argued that conventional indirectness appears to reflect different social meanings in English and Persian and that such differences should be taken into account in EFL instruction and in cross-cultural studies.
\end{abstract}

Key words: Certainty, conventionally indirect strategies, politeness, requestive speech act, Isfahan, Iran

\section{INTRODUCTION}

Studies have described that there are cross-cultural differences between two different speech communities in relation to the type of request and level of directness of request realization (Blum-Kulka and Olshtain 1984; Blum-Kulka et al., 1989; Eslami-Rasekh, 1993; Wierzbicka, 1991). Most of these studies have dealt with request strategies based on the model proposed by Brown and Levinson (1987) few, however have focused on the perception of politeness (Fraser, 1978; Kitao, 1990). To the knowledge, there are virtually no constructive studies on Persian and American English with regard to certainty of compliance of pragmatically equivalent request head acts. This study is intended to contribute to the body of research by comparing the certainty of compliance of request head acts expressed by American and Persian native speakers.

Literature review: It is widely acknowledged that verbal communication is a means of conveying information in addition to establishing, maintaining and terminating social relationship with other people. The rules which determine appropriate behavior are one of the aspects of culture which are clearly reflected in language. The relationship of interactors, their age, the context of situation and several other social factors directly affect language use to degrees determined by the culture.
While extensive studies have been done to discover a universal theory to be applied in diverse cultures and languages (Brown and Levinson, 1987; Grice, 1975; Leech, 1983), the idea that every culture has its own norms has attracted many pragmalinguists who study cross-cultural pragmatics.

With the goal of investigating cross-cultural differences which exist between Persian and English, several studies have been carried out focusing on the realization of different speech acts in an Iranian context. These include apologies (Afghary, 2007) complaints (Eslami-Rasekh, 2004; Salmani-Nodoushan, 2006a), griping (Allami, 2006), invitations (Salmani-Nodoushan, 2006b), requests (Eslami-Rasekh, 1993; Jalilifar, 2009; SalmaniNodoushan, 2006a) and refusals (Moradkhani and Feyzi, 2008). These studies provide readers with a fuller understanding of speech acts in intra- and cross-cultural communication.

In the everyday life, we make and respond to many requests. Making requests is inseparable from politeness strategies, mainly because of the need to avoid threats to $\mathrm{H}$ 's face and to gain compliance from $\mathrm{H}$. Requests have been chosen as the focus of this study because they are one of the many speech acts frequently used in human interaction. Because of the large degree of imposition that making a request places upon one's interlocutor(s), numerous studies have examined its functions to gain understanding of its use and interpretation in different

Corresponding Author: Parisa Abdolrezapour, Department of Applied Linguistics, Faculty of Foreign Languages, University of Isfahan, Hezar Jirib Street, Postal code, 81746-73441, Isfahan, Iran 
cultures. Fukushima (2000), for example conducted a cross-cultural study of polite request strategies in British English and Japanese. $\mathrm{He}$ showed that British and Japanese undergraduate respondents use different politeness strategies when making requests. $\mathrm{He}$ concluded that perceptions of power, social distance and the weight of the imposition influenced politeness strategy choice in the two cultures differently.

Kitao (1990) investigated the level of politeness of various forms of requests made in English as perceived by college-level native speakers of English, Japanese speakers in the United States and Japanese speakers in Japan. He administered a semantic differential questionnaire measuring ten levels of politeness and found no significant difference in perception between American and Japanese but the Japanese in the United States perceived the requests as more polite than the other Japanese. No significant difference in perception of politeness of requests by either sex or age for Japanese and American was found.

In another study, Fraser (1978) determined the level of politeness of different types of request in order of descending deference. He concluded that the sentence with modals are more polite than those without them that positive sentences are more polite than negative ones, that interrogatives are more polite than imperative plustag forms and that past tense is more polite than present tense.

Carrell and Konneker (1981) compared politeness judgments of native speakers of American English and non-native English speakers on a set of request forms, using different mood, tense and modals. Result indicated that grammatical mood makes the greatest contribution to politeness with interrogative being most polite, declarative mood next most polite and imperative least polite. Presence of modals contributes next most to politeness.

There was a high correlation between the native and non-native judgments of politeness. Their finding was similar to that of Tanaka and Kawabe (1982) who found a high correlation between the perception of politeness in requests by Japanese ESL students and Americans. To date, to the best of the knowledge, no study has pointed to the possible cross-cultural difference between American native speakers and Iranian EFL learners with regard to the perception of politeness of American request forms. This study aimed to cover this gap.

Eslami-Rasekh (1993) comparing American and Persian speakers requestive strategies, posited that Persian society is less individualistic and more psychologically dependant on group mentality which leads to strategies of positive politeness as opposed to negative politeness used by American society. More recently, Jalilifar (2009) in a cross-cultural study investigated request strategies used by Iranian EFL learners and Australian native speakers of English. Selection of request situations in his DCT was based on two social factors of relative power and social distance. The findings of his research revealed that as far as social power is concerned EFL learners display closer performance to native speakers. Considering social distance, he found that Iranian EFL learners have not acquired sufficient socio-pragmatic knowledge to display proper social behavior.

Few studies have collected perception data on different aspects of politeness. For example, retrospective reports were used in few studies to supplement the data obtained from the role-play scenarios (Félix-Brasdefer, 2003) and the written questionnaires (DCT) (Henstock, 2003).

In addition, one recent study (Márquez et al., 2005) employed a modified version of the verbal report technique (post-performance questionnaires) to examine the perceptions of conventionally indirect requests between Spaniards and Britons.

Other studies have employed informal techniques for examining the participants' perceptions of politeness in English (Mills, 2003) but most studies to date have not incorporated perception data as part of the research design.

Moreover, with the exception of a few studies that utilized interactional data, the majority have examined written or non-interactional data to analyze the linguistic strategies for expressing requests or refusals in isolated contexts. And since a non-interactive instrument (DCT, closed role play or questionnaire) was used to collect the data, the results in these studies do not reflect the sequential organization of requests and refusals in conversation pairs.

This study which has been motivated by the common factor found in previous request studies, namely, the high preference for conventional indirectness over other requestive strategies in related and unrelated languages (Blum-Kulka and House, 1989), contributes to an understanding of the structure and interactive nature of request speech act in Persian and American that has not been previously examined.

Research question: Using native speaker intuition as a starting point, this study investigates whether conventionally indirect requests mean the same to American English speakers and Iranian speakers. Thus, the following research question is addressed in the present study; do requests which are pragmatically 
equivalent in terms of their indirectness, reflect the same degree of certainty in the likelihood of hearer compliance in American English and Persian?

\section{MATERIALS AND METHODS}

Participants: About 22 native speakers of American English and 30 Persian native speakers were selected based on a stratified sampling procedure. The informants were all university students and they varied in age from 18-26 years with an average of 21. The American participants were students of biology, geography and history at Fresno State University and the Iranian participants were EFL learners at University of Isfahan. Students were chosen as the target population in order to ensure as much homogeneity as possible in terms of educational background, age range, social class and possible future occupation.

Instrumentation: The major proportion of the data was collected via role plays and a questionnaire. The role-play tasks comprised four situations resulting in the elicitation of requests and responses to these requests. These situations had been assessed before conducting the study to make sure that they were comparable in both cultures. First, we had six situations which were used mainly in the Iranian culture. As we needed comparable situations between the two cultures in terms of naturalness, we asked 10 informants from each culture to assess the naturalness of the situations by assigning a number from 1 which shows the situation occurs rarely and 5 which indicates its occurrence is highly probable. T-tests were run to find those situations in which there were differences and two situations were excluded.

The situations depicted in the role-play (Appendix A) reflect everyday occurrences of the type expected to be familiar to both American and Iranian university students. They vary according to the social distance between the speakers, the relative social power of the interlocutors and the rank of imposition of the request. Table 1 shows a description of the contextual variables.

In these situations, social distance is regarded as how well interlocutors know each other: either close (-SD) or distant $(+\mathrm{SD})$; social power, on the other hand, refers to the vertical disparity between the participants in a hierarchical structure (Scollon and Scollon, 2001). Then

Table 1: Classification of situations according to contextual and social variables

\begin{tabular}{lccc}
\hline Situation & Social power & Social distance & Rank ofimposition \\
\hline Borrow a book & $\mathrm{S}<\mathrm{H}$ & $+\mathrm{SD}$ & Low \\
Borrow a pen & $\mathrm{S}=\mathrm{H}$ & $+\mathrm{SD}$ & Low \\
Type the letters & $\mathrm{S}=\mathrm{H}$ & $-\mathrm{SD}$ & High \\
Give a lecture & $\mathrm{S}>\mathrm{H}$ & $+\mathrm{SD}$ & High \\
\hline
\end{tabular}

$\mathrm{S}=$ Speaker, $\mathrm{H}=$ Hearer, $\mathrm{SD}=$ Social Distance the questionnaire (Appendix B for situation one) was constructed based on the role plays and the request head acts used. These head acts were the same for all situations to be able to find the effect of social variables such as social distance or social power on perception of politeness by informants.

Data collection and coding procedure: Following the assessment of the role plays, subjects participated in the role plays. A tape recorder was made use of to audiorecord the participants' role plays. Immediately after each role play, they were asked to participate in the stimulated recall section in which they listened to their voice and talked about their perception of the request compliance at the time of performing the role plays. The requestor was required to recall how certain he/she was that the requestee would comply with the request.

Then the participants from both cultures completed the questionnaires constructed based on the role plays. We had four situations in the questionnaire and each situation was followed by six request head acts (Appendix $\mathrm{B}$ for situation one). The informants had to rate each case by writing next to it a figure from 1-5. Then, for each case and each participant a mean was calculated and in the last stage, means of all informants of each group for each situation were compared. T-tests were run to see whether the mean scores of the two groups in different situations were significantly different or not.

\section{RESULTS}

This study presents results of data analysis related to each situation with regard to the perception of request compliance among the Iranian and the American requestors when requesting a person in different situations and how these perceptions differ across Iranian and American cultures. Then, the results of the stimulated recall technique which was used to confirm the answer to the first research question are reported. The analysis of the role play data shows that requests used by both groups in all four situations were mainly characterized by the use of the conditionally indirect utterances (e.g., could you give your lecture sooner). This is described below in the extracts from the corpus.

\section{American extracts: \\ Example 1: (Borrow a book)}

A: Could I possibly borrow the book that you recommended to me?

B: Well, it is in my car. I'll bring it to your class.

A: Thanks a lot. See you then.

Example 2: (Borrow a Pen)

A: Excuse me, could you give me your pen so that I can fill out this form? 
The Soc. Sci., 5 (4): 332-339, 2010

B: Sure, here you are.

A: Thanks.

Example 3: (Type the letters)

A: Jack. Would you type these letters for me?

B: Well, I have to send these mails, I will type them then. Is that ok with you?

A: That is all right.

Example 4: Situation 4 (Give a lecture)

A: Can you perhaps give your lecture tomorrow?

B: Definitely. You are quite welcome.

Example 5: (Borrow a book)

A: Bebakhshid ostâd .... Hafteye pish ye ketâb be man mo'arefi kardid vali alân ke raftam ketâbkhune didam bastast. Mishe ketâbetun ro gharz begiram?

B: Albate, bezâr barât biâramesh.

English translation

A: Sorry professor ..... Last week you introduced a book to me but when I went to the library it was closed. Is it possible to lend me your book?

B: Sure, Let me bring it for you.

Example 6: (Borrow a Pen)

A: Bebakhshid.... Mishe khodkaretun ro gharz begiram?

B: Um ..... Bale, Hatman.

A: Mamnoon.

English translation

A: Sorry..... Is it possible to borrow your pen?

B: Um.... Yes, of course.

A: Thanks.

Example 7: (Type the letters)

A: Mishe in nâmehâ ro type koni? Khodam vaght nadâram bâyad beram kârâye digaro anjâm bedam.

B: Albate... Khoshhâl misham kâri barâye in proje anjâm bedam.

English translation

A: Can you type these letters for me? I do not have time. I should go and do the rest of the work.

B: Sure... I would be happy to do something for this project.

Example 8: (Give a lecture)

A: Aghâye Rezaee... man hafteye dige ye hamâyesh bâyad beram nemitunam sare kelâsetun biâm. Mituni lectureto zudtar âmâde koni?

B: Hatman ostâd

English translation

A: Mr. Rezaee... I have to go to a conference next week;

I can't come to your class. Can you prepare your lecture sooner?

B: Sure professor
Table 2: Descriptive statistics of situation one

\begin{tabular}{llll}
\hline Groups & $\mathrm{N}$ & Mean & SD \\
\hline Iranian & 30 & 2.50 & 0.68 \\
American & 22 & 4.00 & 0.61 \\
\hline
\end{tabular}

Table 3: Independent t-test for situation one

\begin{tabular}{llll}
\hline $\mathrm{T}$ & $\mathrm{Df}$ & Sig. (2-tailed) & Mean difference \\
\hline
\end{tabular}

*Indicates that the calculated means of the two groups are significantly different $(\mathrm{p}<0.05)$

Then, for each case and each participant a mean was calculated (it should be noted that the obtained means were of an interval scale) and in the last stage, means of all informants for each situation were compared. T-tests were used to see whether the differences between the means of the two cultures for different situations were significant or not. The reason is that we aimed to find whether the certainty levels varied across different situations and to find which factors might affect the requestors' certainty of compliance by means of the interviews carried out.

Table 2 shows the descriptive statistics for mean scores in the first situation. As it is shown in Table 2, the mean scores are different across the two groups; however, to establish whether or not the differences between mean scores of the two groups were statistically significant an independent-sample t-test was performed. Results shown in Table 3 point to the statistically significant difference between the two groups.

The reason for this difference was found by conducting interviews and analyzing the answers to the second question of the questionnaire. In the postperformance interview, the Iranian informants tended to attribute their low level of certainty to the social power difference between the participants in this situation. They explained that they had to be polite when asking a professor and they should have the necessary level of formality.

Though, they intended that in Iran, professors do their best to help their students and they have no problems whatsoever in facilitating materials to students, they told that they would try to be more polite and put less imposition. This finding is in line with the answer to the question posed in the interview: to what extent were you sure that the addressee would comply with your request in this situation? Most of the participants said that it was the social power of the professor that affected their degree of certainty in request compliance.

One response that most of them gave in the stimulated recall section regarding the degree of certainty they had when requesting is given: Bishtar say dAshtam ke moadabAne darkhAste khodamo matrah konam va ye jur neshun bedam ke be ketAb niAze fori dAram chun injuri ehtemAle rad shodane darkhAstam kamtar bud. 
The Soc. Sci., 5 (4): 332-339, 2010

Table 4: Descriptive statistics of situation two

\begin{tabular}{llll}
\hline Group & $\mathrm{N}$ & Mean & $\mathrm{SD}$ \\
\hline Iranian & 30 & 4.66 & 0.49 \\
American & 32 & 3.09 & 0.75 \\
\hline
\end{tabular}

Table 5: Independent t-test for situation two

\begin{tabular}{lccc}
\hline $\mathrm{T}$ & Df & Sig. (2-tailed) & Meandifference \\
\hline 8.96 & 50 & 0.00 & 1.54 \\
\hline
\end{tabular}

*Indicates that the calculated means of the two groups are significantly different $(\mathrm{p}<0.05)$

Table 6: Descriptive statistics of situation three

\begin{tabular}{llll}
\hline Group & $\mathrm{N}$ & Mean & $\mathrm{SD}$ \\
\hline Iranian & 30 & 4.83 & 0.37 \\
American & 22 & 4.86 & 0.35 \\
\hline
\end{tabular}

English translation: I was trying to politely let him know that I needed to take the book as the chances of being refused were lower in that case. But American informants were more concerned about social distance and degree of imposition of their requests and contrary to what Iranian informants said few of them chose social power of the requestee as one of the factors that influenced their certainty of compliance.

Independent $t$-tests were performed to see whether the difference between the means of the scores of the Iranian informants and that of American informants in the second situation were significant or not. Table 4 shows the results of the descriptive statistics for the second situation and Table 5 the results of the t-test.

Analyzing the replies provided for the questionnaire showed that American informants believed that the addressee might not wish to lend his/her pen. They intended that it was quite natural for some people to be very apprehensive about lending their belongings; though they explained that pens were usually rather cheap. But Iranian speakers said that they would have a non-imposing request and that since the pens were usually cheap it might be quite expectable that the requestee would comply with their requests. The answer given by most of them in the stimulated recall section was: Ye darkhAste kheili kuchike va mosalaman age shakhse darkhAst shavande khodkAresho 1Azem nadAshte bAshe hatman uno gharz mide.

English translation: It is a very low imposing request and if the requestee is not in the need of his pen he will definitely lend his pen. In order to answer the research question for the third situation which dealt with the interaction between two students who knew each other, mean scores were calculated.

Table 6 shows the descriptive statistics for mean scores. As it is displayed in the table, the mean scores are very similar across the two groups; however to establish whether or not the differences between mean scores were
Table 7: Independent t-test for situation three

\begin{tabular}{llcc}
\hline$T$ & Df & Sig. (2-tailed) & Mean difference \\
\hline-0.294 & 50 & 0.77 & -0.0303 \\
\hline
\end{tabular}

Table 8: Descriptive statistics of situation four

\begin{tabular}{llll}
\hline Groups & $\mathrm{N}$ & Mean & $\mathrm{SD}$ \\
\hline Iranian & 30 & 4.80 & 0.40 \\
American & 22 & 3.54 & 0.80 \\
\hline
\end{tabular}

Table 9: Independent t-test for situation four

\begin{tabular}{llll}
\hline $\mathrm{T}$ & $\mathrm{Df}$ & Sig. (2-tailed) & Mean difference \\
\hline 9.20 & 50 & $0.00^{*}$
\end{tabular}

*Indicates that the calculated means of the two groups are significantly different $(p<0.05)$

statistically significant an independent-sample t-test was performed. Results shown in Table 7 do not point to any statistically significant difference between the two groups. This fact is confirmed by the result of the t-test which shows that there is no significant difference between the means of scores of the subjects in the two groups ( $\mathrm{p}=0.770>0.05)$.

When asked to explain the reason, both groups of informants claimed that the two interlocutors had the same social power, one of the addressee's duties was to do the requests of his supervisor and all the members of the group should help each other to finish the project. Followed, we will go through the response provided by one of the Iranian participants regarding the degree of certainty he had in this situation: Chun har domun midoonim ke yeki az vazAyefe un shakhs type kardane nAmehast pas ehtemAle inke bekhAd darkhAste mano rad kone kheili pAeene.

English translation: Since both of us know that one of his duties is typing the letters, so the chances of being refused are very low (Table 8 ). Once again, to see whether the difference between 4.800 , the mean for Iranian group and 3.5455, the mean for American group, is significant or not we used an independent t-test (Table 9).

In this situation, Iranian informants once again expressed higher degree of certainty than their American counterparts. When asked to explain what caused this certainty, they said that most students because of the higher power of the professor tend to avoid refusing so they had a high expectation of compliance by the addressee. And when answered to the second question of the questionnaire, they said that higher social power of the addressee made them certain that their request would be granted. While the American informants said that having higher power would not necessarily lead to being more certain that the request would be granted.

One response that most of Iranian informants gave in the stimulated recall section regarding the degree of certainty they had when requesting is given below: 
Mogheiate ejtemaee yek ostad baes mishe ke daneshju darkhAstesho rad nakone hata age anjAme un kAr barAsh sakht bashe say mikone mokhAlefat nakone.

English translation: The social power of the instructor lead to the fact that the student won't refuse him even though doing that work is difficult; he would do his best to not refuse. In general, the above tables show that a notable difference can be found between the American and Iranian informants' answers in situation 1 (borrow a book from professor), 2 (borrow a pen from a student) and 4 (ask a student to give lecture).

As said before, the differences in each situation were supported by the interviews administered after the role plays. Except for one situation, (i.e., situations 3 ) in which the informants expressed nearly the same degree of certainty, in the rest a significant difference could be found between the certainty levels in both the answers to the questionnaire and the response to the interviews. The possible reason for these differences will be discussed in the following section.

\section{DISCUSSION}

The current study was designed to find the effects of the wording of the requests on interlocutors' perception of request compliance. The speech acts of this study were analyzed following Blum-Kulka et al. (1989) coding scheme. As expected, most participants used the indirect strategy. The reason might be the fact that the participants were all educated people and the situations used in the study were related to student life. So this part, partly confirmed Eslami-Rasekh (1993)'s finding which showed that conventional indirect strategy is more prevalent in these two cultures.

Moreover, the analysis of the data showed that both American and Iranian speakers varied the way they frame their requests according to the social power and social distance between the interlocutors. The data collected for the first questionnaire (Appendix B) showed that although request head acts such as: Can you lend me your pen? and its Iranian equivalent khodkareto be man gharz midi? showed morphosyntactic and semantic equivalencies and express the same level of indirectness, the assumed expectations of compliance by the speakers of the two cultures were different.

In such situations, Iranian speakers said that by uttering requests, the speaker was almost certain that his/her hearer would comply with the request while American speakers were not as certain as Iranian speakers. This shows that requests which show almost complete morphological, syntactic, semantic and pragmatic equivalencies might mean different things in different cultures. The interviews administered after each role play which addressed the factors that contributed to the responses participants provided in each situation, supported the responses got from the questionnaires. They helped us to learn what the respondents actually perceived about each situation (e.g., what they perceived about the compliance of request) and how their perceptions influenced their responses (Cohen, 2004). In the current study, an analysis of the participants' answers in the interviews and the ones to third question of the questionnaire helped us to find what Iranian and American participants perceived about request compliance with regard to the situation and their addressee.

The results of this part of our study have shown that there is a significant difference between speakers' perceptions of compliance when realizing conventionally indirect requests. Analyzing the situations revealed that the differences were in the situations that social power and social distance were concerned i.e., in situations one and four where there was an interaction between the professor and student $(+\mathrm{SP})$ and situation two that the interlocutors did not know each other well (+SD) and only in the case that the interlocutors knew each other (-SD) i.e., situations three which were interaction between two classmates, means of certainty expressed by two groups were nearly the same and the differences between the means were not significant.

\section{CONCLUSION}

As explained in the study, Iranian requestors were more concerned with the social power of their requestee and this fact influenced the degree of certainty expressed by them in situations where social power was involved. Moreover, in situations that interlocutors knew each other well both groups expressed the same degree of certainty regarding request compliance.

Overall, the data collected in this study could afford enough evidence to argue that, based on the category proposed by Scollon and Scollon (2001), Iranian cultural system may be regarded as a hierarchical one in terms of politeness. Since subjects, the data revealed, were more concerned with the interlocutors' power and when they had to encounter situations which involved power, they considered their interlocutors' power as one key factor which affected their certainty with respect to compliance or rejection. On the contrary, American cultural system appeared to be based on deference politeness system as the interlocutors saw themselves at the same social level with no interlocutor exerting power over the other. This can be proven by the fact that even in the last situation the professor who had higher power was concerned about not being accepted. 
The differences found in the degree of certainty expressed by two cultures should be taken into account in EFL instruction and in cross-cultural studies. The logical conclusion that follows from our findings is that it makes sense for school systems to seek out and utilize principles of speech act behavior for students in EFL classrooms in an effort to promote their communicative competence. Suggestions are made to investigate the linguistic realization and social strategies of participants of different ages, sexes, educational levels and socioeconomic backgrounds.

\section{APPENDIX}

\section{Appendix A (Role plays)}

Instructions: You will be asked to read some brief situations in which there are two participants. You will role play one of the participants and another person will role play the other. You both know who you are and where you are however, one of you does not know what the other one wants. The interaction will be recorded. You will have to act as you would in an actual situation: you will have to act the situation and interact with the other person, thus expect there could be some social chat. Do not think too much and try to be as spontaneous as possible.

Situation 1 (Borrow a book)

Informant A:

You are a university student. Your lecturer recommended you a book which would be helpful for your research. The library is closed and the only person who has the book is your lecturer. On the way to his/her office you meet $\mathrm{him} / \mathrm{her}$ in the hallway. What do you say?

Informant B:

You are a university lecturer. While leaving your office you meet one of your students in the hallway. Respond to him/her.

Situation 2 (Borrow a pen)

Informant $\mathrm{A}$ :

For registration you need to fill out a couple of forms. You search all of your pockets and you can't find a pen. You want to ask another student who is sitting next to you in the department hall. What do you say?

Informant B:

You are sitting in the department hall. The person sitting next to you talks to you. Respond to him/her.

Situation 3 (Type the letters)

Informant A:

You have been put in charge of a project at university. You go to the desk of a classmate of yours who cooperates with you and ask him/her to type a few letters for you. What do you say to him/her?

Informant B:

Your classmate has been put in charge of a project at university. S/he comes to your desk and talks to you. Respond to him/her.

Situation 4 (Give a lecture)

Informant A:

You are a professor in a university. Because you have to attend an important conference, you ask your student to give his lecture earlier than scheduled. What do you say to him/her?

Informant B:

You are a university student. One of your professors comes to you and talks to you. Respond to him/ her.

\section{Appendix B}

English version

Age: .......... Sex:

Place of birth: ......... Field of study:

I. Below you will find a situation, for which a speaker has made requests in several different ways. How certain do you think the speaker is that hisher request would be granted in each case?
Please rate the degree of certainty you have for each case by putting a number from 1 (absolutely uncertain) to 5 (absolutely certain)

Situation 1

A university student needs to get a book from the library to do his/ her research. The library is closed and only one person has the book, hisher lecturer who recommended it. When the student is walking down one of the corridors in the university, he/she bumps into the lecturer who has the book.

(a) I was just wondering if you have the book and I could borrow it. -------

-----

(b) If you are not using your copy, could you lend it to me?

(c) I was wondering whether or not you could possibly lend me the book?

(d) Can I possibly borrow the book you recommended to me?

(e) I was wondering if it would be possible to borrow the book from you.-

(f) Is it all right if I borrow the book you recommended to me? ------------

II. Which of the following factors might influence the degree of certainty that you have that your request will be granted?

a. Social distance (i.e. how well you know each other not how long) between you and the addressee

b. Social power of the addressee

c. Rank of imposition of your request

If there are any other factors write them here.

\section{REFERENCES}

Afghary, A., 2007. A sociopragmatic study of apology speech act realization patterns in Persian. Speech Commun., 49: 177-185.

Allami, H., 2006. A sociopragmatic analysis of griping: The case of Iranian students. Linguistic J., 1: 59-76.

Blum-Kulka, S. and E. Olshtain, 1984. Requests and APOLOGIES: A cross-cultural study of speech act realization patterns (CCSARP). Applied Linguistics, 5: 196-213.

Blum-Kulka, S. and J. House, 1989. Cross-Cultural and Situational Variation in Requesting Behavior. In: Cross-cultural Pragmatics: Requests and Apologies, Blum-Kulka, S., J. House and G. Kasper (Eds.). Ablex Publisher, Norwood, NJ., pp: 123-154.

Blum-Kulka, S., J. House and G. Kasper, 1989. Crosscultural Pragmatics: Requests and Apologies. 1st Edn., Ablex Publication, Norwood, New Jersey.

Brown, P. and S. Levinson, 1987. Politeness: Some Universals in Language. Cambridge University Press, Cambridge, UK.

Carrell, P.L. and B.H. Konneker, 1981. Politeness: Comparing native and nonnative judgments. Language Learning, 31: 17-30.

Cohen, A.D., 2004. Assessing Speech Acts in a Second Language. In: Studying Spanish to Inform Second Language Learning, Boxer, D. and A. Cohen (Eds.). Multilingual Matters, Clevedon, pp: 302-327.

Eslami-Rasekh, Z., 1993. A cross-cultural comparison of the requestive speech act realization patterns in Persian and American english. Pragmatics Language Learning, 4: 85-101. 
Eslami-Rasekh, Z., 2004. Face keeping strategies in reaction to complaints: English and Persian. J. Asian Pacific Commun., 14: 181-198.

Fraser, B., 1978. Acquiring social competence in a second language. RELC J., 9: 1-21.

Fukushima, S., 2000. Requests and Culture: Politeness in British English and Japanese. 3rd Edn., Verlag Peter Lang, USA., ISBN-13: 978-3039100453, pp: 315.

Félix-Brasdefer, J.C., 2003. Declining an invitation: A cross-cultural study of pragmatic strategies in Latin American Spanish and American English. Multilingua, 22: 225-255.

Grice, H.P., 1975. Logic and Conversation. In: Syntax and Semantics3: Speech Acts, Cole, P. and J.L. Morgan (Eds.). Academic Press, New York.

Henstock, M.I., 2003. Refusals: A language and cultural barrier between Americans and Japanese. Ph.D. Dissertation, Purdue University. http://docs.lib. purdue.edu/dissertations/AAI3113813/.

Jalilifar, A., 2009. Request strategies: Cross-sectional study of Iranian EFL learners and Australian native speakers. English Language Teaching, 2: 46-61.

Kitao, K., 1990. A study of Japanese and American perceptions of politeness in requests. Doshisha Stud. English, 50: 178-210.

Leech, G., 1983. Principles of Pragmatics. 1st Edn., Longman Publisher, New York.
Mills, S., 2003. Gender and Politeness. Cambridge University Press, Cambridge.

Moradkhani, S. and R. Feyzi, 2008. Refusal strategies among Iranian EFL learners: Males vs. females. International TELLSI Conference. Guilan University, Guilan.

Márquez, R.R., I. Rainey and G. Fulcher, 2005. A comparative study of certainty and conventional indirectness: Evidence from British English and Peninsular Spanish. Applied Linguistics, 26: 1-31.

Salmani-Nodoushan, M.A., 2006a. Conversational strategies in farsi complaints: The case of Iranian complainees. Int. J. Language, 18: 9-14.

Salmani-Nodoushan, M.A., 2006b. A comparative sociopragmatic study of ostensible invitation in English and Farsi. Speech Commun., 48: 903-912.

Scollon, R. and S. Scollon, 2001. Intercultural Communication. 2nd Edn., Blackwell Publishing, London.

Tanaka, S. and S. Kawabe, 1982. Politeness strategies and second language acquisition. Stud. Second Language Acquisition, 5: 18-33.

Wierzbicka, A., 1991. Cross-cultural Pragmatics: The Semantics of Human Interaction. Trends in Linguistics Studies and Monographs. 2nd Edn., Mouton De Gruyter, Berlin, ISBN-13: 978-3110177695, pp: 502 . 